\title{
Application of the PDCA cycle for standardized nursing management in a COVID-19 intensive care unit
}

\author{
Yihong Chen", Jili Zheng", Dingyun Wu, Yuxia Zhang, Ying Lin \\ Department of Nursing, Zhongshan Hospital, Fudan University, Shanghai 200032, China \\ Contributions: (I) Conception and design: Y Chen; (II) Administrative support: Y Zhang, Y Lin; (III) Provision of study materials or patients: J Zheng; \\ (IV) Collection and assembly of data: D Wu; (V) Data analysis and interpretation: Y Chen; (VI) Manuscript writing: All authors; (VII) Final approval \\ of manuscript: All authors. \\ "These authors contributed equally to this work. \\ Correspondence to Yuxia: Zhang; Ying Lin. Zhongshan Hosital, Fudan University, Shanghai 200032, China. \\ Email: zhang.yuxia@zs-hospital.sh.cn; lin.ying@zs-hospital.sh.cn.
}

Background: Nursing quality is an integral part of health care quality and one of key performance indicators (KPIs) for health care management. The Plan-Do-Check-Act (PDCA) cycle is a management tool for continuous improvement of a business's products or processes. It can be applied to standardize nursing management and thus improve the nursing quality and increase the survival rate of patients. This study assessed the value of the PDCA cycle in standardizing nursing management in an intensive care unit (ICU) for patients with severe coronavirus disease 2019 (COVID-19).

Methods: The status quo of the ICU was analyzed, and the relevant issues and countermeasures were proposed. The PDCA cycle was applied to standardize the nursing management in the ICU.

Results: Nine measures were proposed and applied to improve the management of the COVID-19 ICU: defining the clean or contaminated areas, use of self-designed shoe storage cabinets, defining staff roles and responsibilities, establishing the staffing structure, staff training, placing items at fixed locations, improving shift handover, use of bulletin boards for listing key points, and use of reserved drugs cabinets. The virus contamination awareness, professional skills, awareness of duties and responsibilities, and quality and performance of nursing were remarkably improved 2 weeks after the implementation of the above countermeasures.

Conclusions: The PDCA cycle helps to standardize nursing management in COVID-19 ICU by developing and applying effective nursing management approaches.

Keywords: Plan-Do-Check-Act cycle (PDCA cycle); coronavirus disease 2019 (COVID-19); nursing management; standardization

Submitted Apr 10, 2020. Accepted for publication May 20, 2020.

doi: 10.21037/apm-20-1084

View this article at: http://dx.doi.org/10.21037/apm-20-1084

\section{Introduction}

Nursing quality is an integral part of health care quality and one of key performance indicators (KPIs) for health care management $(1,2)$. The Plan-Do-Check-Act (PDCA) cycle is a repetitive four-stage model for continuous improvement in quality management $(3,4)$. It can be applied to standardize nursing management $(5,6)$ and thus improve the nursing quality and increase the survival rate of patients $(7,8)$.

In January 2020, our hospital (Zhongshan Hospital of Fudan University) sent its aid team to Hubei Province to support the prevention and control of coronavirus disease 2019 (COVID-19). The team was designated to treat patients with severe COVID-19 admitted to the intensive care unit (ICU) of the Department of Infectious Diseases 
of Eastern Campus, Renmin Hospital of Wuhan University $(9,10)$. In order to effectively combat the epidemic and improve the quality of nursing care for critically ill patients, a nursing management team was established, which carefully analyzed the status quo of the ICU and applied the PDCA Cycle to standardize and improve the quality and performance of nursing.

We present the following article in accordance with the SURGE reporting checklist (available at http://dx.doi. org/10.21037/apm-20-1084).

\section{Methods}

Ethical approval for this study was waived as this study was performed during the COVID-19 epidemic. The nursing team approved the use of the nursing sheets and pictures relevant to this study for this article. All the medical staff participating in this study signed the informed consent documents.

\section{Status quo analysis}

No standardized nursing management policies had been applied in the ICU when the aid team took charge in February 2020. A nursing management team including 12 nursing staff members from Zhongshan Hospital was established, and a ward management standardization program was carried out by applying the PDCA cycle.

\section{Identifying problems and proposing suggestions}

Surveys were carried out in February, 2020, and the results were summarized.

\section{Problems}

Problems identified during the surveys included (I) contaminated areas not being clearly defined, (II) the roles and responsibilities of nursing staff being unclear, (III) the disorderly placement of items, (VI) ineffective shift handover, and $(V)$ long wait times for drugs.

\section{Suggestions}

To address these issues, the following countermeasures were suggested: (I) defining the clean and contaminated areas, (II) use of self-designed shoe storage cabinets, (III) defining the staff's roles and responsibilities, (IV) establishing the staffing structure, (V) carrying out staff training, (VI) placing items at fixed locations, (VII) changing the shift handover modes, (VIII) improving handover communication by using bulletin boards, and (VIIII) using reserved drug cabinets.

\section{PDCA cycle}

\section{Plan}

(I) The contaminated areas were not clearly defined: although the ICU had been rebuilt as a quarantine ward, there was no clear division of different areas; as a result, the contaminated area was not clearly defined and the patient flow was poorly designed. The countermeasure was to divide the ICU into contaminated areas, semi-contaminated areas, and clean areas, and to use self-designed shoe storage cabinets.

(II) The roles and responsibilities of nursing staff were unclear: the medical staff came from different places, with varied roles and responsibilities; there was no clearly appointed managing staff, and the professional capabilities and skills also differed among the staff members. The countermeasures adopted were to clarify the roles and responsibilities of each nurse, establish staffing structure, and conduct staff training.

(III) Placemen of items was disordered: the items were placed casually because there were no designated places for items. The countermeasure was to place items at fixed locations.

(IV) Shift handover was ineffective: the large amount of patients in the ICU led to information being lost during shift handover. In addition, communication was not efficient because there was too much information. The new team changed the shift handover mode and used bulletin boards to list the key points.

(V) Drug transport was time-consuming: a lack of personnel led to an inefficient transportation of drugs. Reserved drugs cabinets were used to solve this problem.

Do

(I) Regular updates were instituted. With a focus on the nursing problems, regular meetings were held to propose measures for increasing the management awareness of the nursing staff and to define job responsibilities.

(II) Specialist nursing teams were established. A detailed work plan was developed for each group. Regular training sessions were held to improve the professional skills for the management of critically ill patients. 


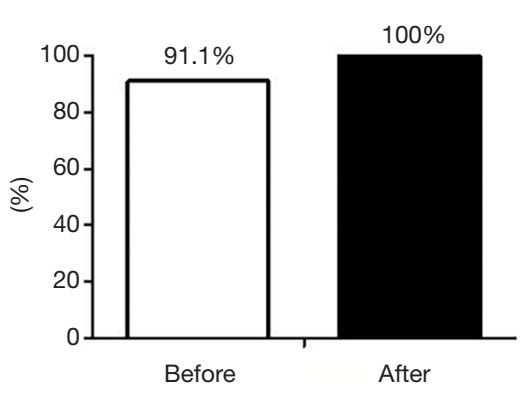

Figure 1 The awareness of medical staff of contaminated areas before and after the implementation of the countermeasures. The awareness rate increased from $91.1 \%$ to $100 \%$ after the countermeasures were implemented, indicating all staff were aware of these areas and could follow a safe workflow.

\section{Check}

(I) The head nurse and quality control personnel ensured that the quality inspection and nursing care for each patient could be fully implemented. The head nurse conducted ward rounds at least once a week.

(II) The performance of nursing staff was evaluated by questionnaire-based survey, on-site survey, and written examinations.

\section{Act}

(I) Feedback including countermeasures and improvements were offered for the existing problems. The head nurse and quality control staff followed up the identified problems and took measures to ensure the effectiveness of patient care and staff training.

(II) Any new or persistent problems were brought into the next round of the PDCA cycle for improvement. For example, the nursing department conducted timely discussions on the problems in the work processes or policies and made corresponding revisions.

\section{Results}

\section{Defining clean or contaminated areas}

The awareness of medical staff on the concept of contaminated area was assessed within 2 weeks after the implementation of the countermeasures. As shown in Figure 1, after the countermeasures were implemented, the awareness rate increased from $91.1 \%$ to $100 \%$; that is, all staff members were aware of these areas and could follow a safe workflow.

\section{Use of self-designed shoe storage cabinets}

As shown in Figure 2A,B, waste cardboard boxes were used to make shoe storage cabinets, which allowed the orderly storage and retrieval of working shoes and the delineation of clean and contaminated areas.

As shown in Figure 2C, the proportion of medical staff who could store their shoes in orderly fashion was at $87.3 \%$ before the use of self-designed shoe storage cabinets and rose to $100 \%$ after.

\section{Defining the staff's roles and responsibilities}

The workflow of each shift in the ICU was redesigned (Figure $3 A$ ) to ensure that all the nursing work in the ward was carried out in an orderly manner. The awareness of medical staff of their roles and responsibilities was surveyed by using a self-designed questionnaire form within 2 weeks after the implementation of the countermeasure. As shown in Figure 3B, the awareness level increased from $87.9 \%$ to $100 \%$; that is, all the medical staff clearly knew their roles and responsibilities.

\section{Establishing the staffing structure}

As shown in Figure 4A, specialist nursing groups were established based on the professional background and skills of nursing staff. The awareness of medical staff of their posts was surveyed by using a self-designed questionnaire form within 2 weeks after the implementation of the countermeasure. As shown in Figure 4B, the awareness level increased from $90.6 \%$ to $100 \%$; that is, all the medical staff clearly knew their post duties.

\section{Staff training}

Staff members in all the intensive care rooms were trained on the first aid operations and the use of special instruments/catheters. Small training videos were recorded and shared in WeChat groups to ensure the homogeneity among nursing staff. Patient safety and quality of nursing care were always the top priorities (Figure 5A).

The professional skills of medical staff were evaluated by using a written examination within 2 weeks after the implementation of the countermeasure. As shown in Figure $5 B$, the average score increased from 73.2 to 92.1 after the countermeasure was implemented. 

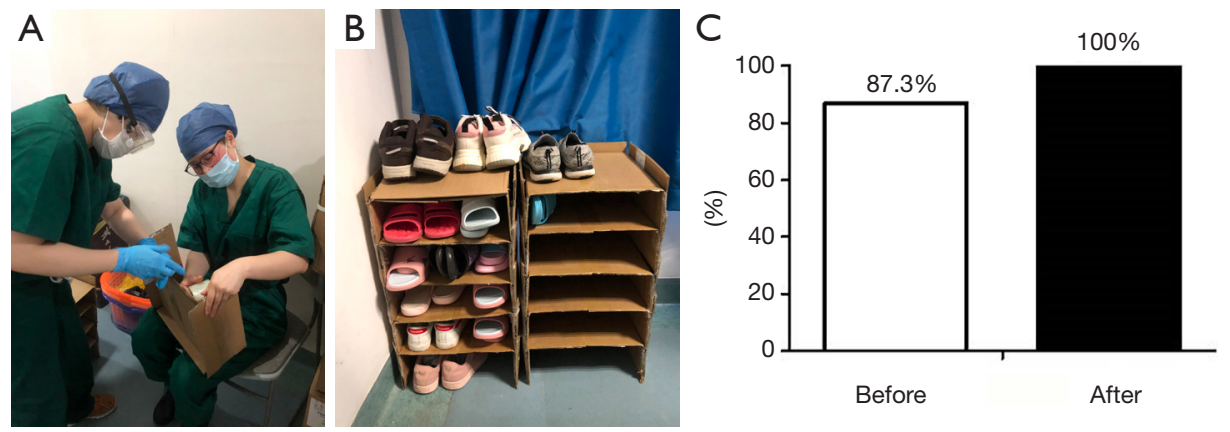

Figure 2 Proportion of medical staff who could store their shoes in orderly fashion before and after the use of self-designed shoe storage cabinets. (A) Waste cardboard boxes were used to make shoe storage cabinets, (B) which allowed the orderly storage and retrieval of working shoes and the delineation of clean and contaminated areas. (C) The proportion of medical staff who could store their shoes in orderly fashion increased from $87.3 \%$ to $100 \%$.
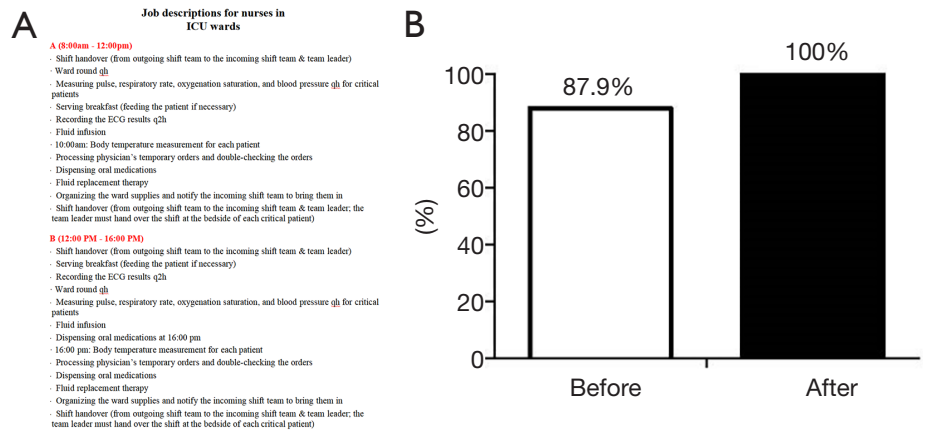

Figure 3 Awareness of medical staff of their roles and responsibilities before and after the implementation of the countermeasure. (A) The workflow of each shift in the ICU was redesigned. (B) The awareness of medical staff of their roles and responsibilities increased from $87.9 \%$ to $100 \%$; indication all the medical staff clearly knew their roles and responsibilities was surveyed by using a self-designed questionnaire form within 2 weeks after the implementation of the countermeasure.

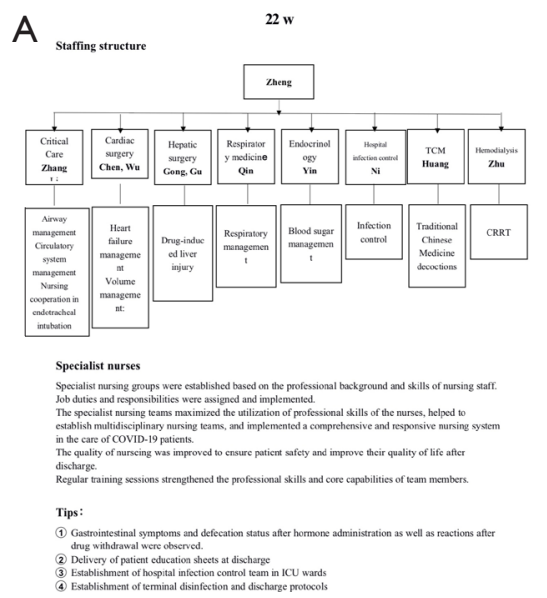

B

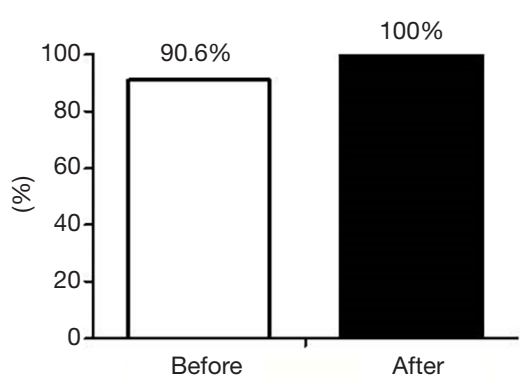

Figure 4 Awareness of medical staff of their posts before and after the implementation of the countermeasure. (A) Specialist nursing groups were established based on the professional background and skills of nursing staff. (B) The awareness of medical staff of their posts increased from $90.6 \%$ to $100 \%$; indicating all the medical staff clearly knew their post duties. 

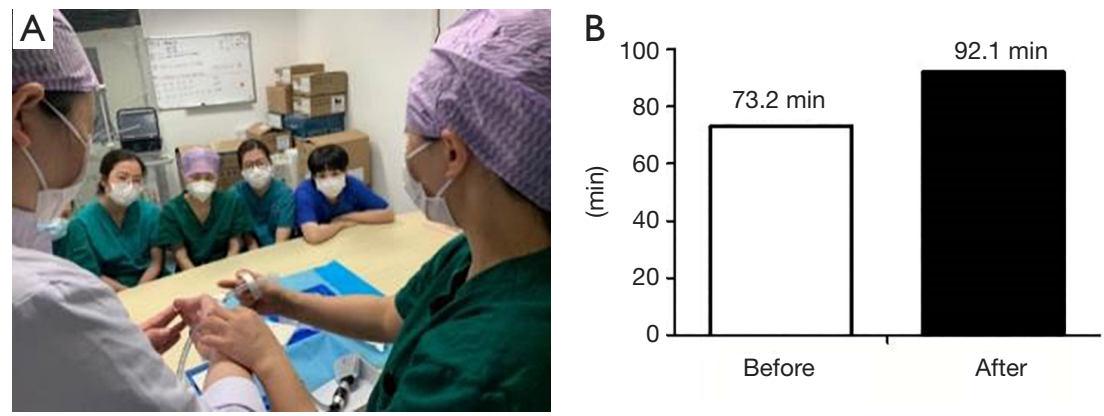

Figure 5 Professional skills of medical staff before and after the implementation of the countermeasure. (A) Staff members in all the intensive care rooms were trained on the first aid operations and the use of special instruments/catheters. (B) The professional skills score increased from 73.2 to 92.1 after the countermeasure was implemented.
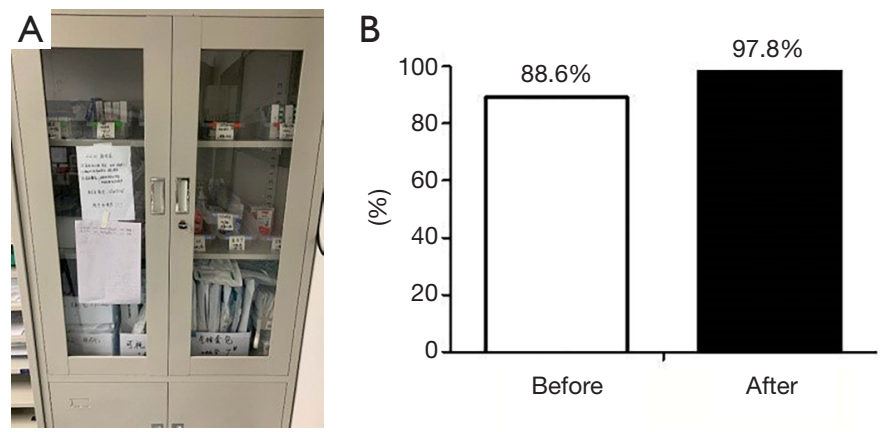

Figure 6 Efficiency of medical staff in locating items. (A) All items were placed at fixed locations, and (B) the efficiency of medical staff in locating items increased from $88.6 \%$ to $97.8 \%$.

\section{Placing items at fixed locations}

Placing all items at fixed locations helped the medical staff to quickly locate a specific item and thus facilitated the execution of various duties (Figure $6 A$ ). As shown in Figure $6 B$, the efficiency of medical staff in locating items increased from $88.6 \%$ to $97.8 \%$ within 2 weeks after the implementation of the countermeasure.

\section{Change of shift handovers}

The use of the Situation, Background, Assessment, Recommendation (SBAR) handover sheet (Figure 7A) allowed the nursing staff to better understand the dynamic changes of patients' conditions, with more clearly presented the key points. The awareness of medical staff on SBAR handover was evaluated within 2 weeks after the implementation of the countermeasure. As shown in Figure $7 B$, the awareness rate increased from $85.7 \%$ to $100 \%$.

\section{Improved handover communication by using bulletin boards}

As shown in Figure $8 A, B$, a self-made memo bulletin board was used to list the key points in daily work. The awareness of medical staff on key points was evaluated within 2 weeks after the implementation of the countermeasure. As shown in Figure $8 C$, the awareness rate increased from $81.1 \%$ to $98.6 \%$.

\section{Use of reserved drugs cabinets}

Reserved drugs cabinets were used (Figure 9A,B). The waiting time for drug transport was assessed within 2 weeks after the countermeasure was implemented (Figure 9C). It dropped from 60 to $5 \mathrm{~min}$.

\section{Discussion}

The PDCA Cycle has been successfully applied to nursing 


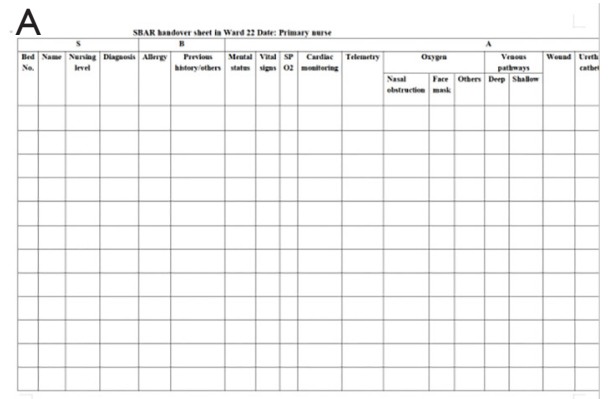

B

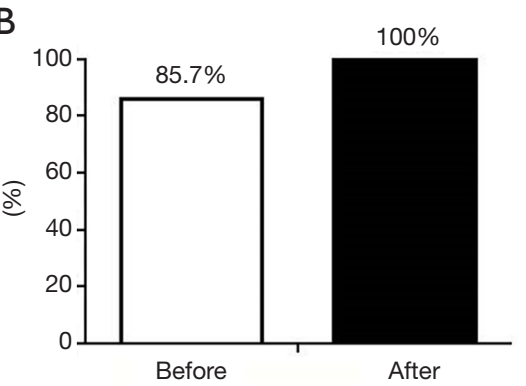

Figure 7 Awareness of medical staff on SBAR handover before and after the implementation of the countermeasure. SBAR, Situation, Background, Assessment, Recommendation. SBAR handover sheet (A) allowed the nursing staff to better understand the dynamic changes of patients' conditions, (B) the awareness rate on SBAR handover increased from $85.7 \%$ to $100 \%$.
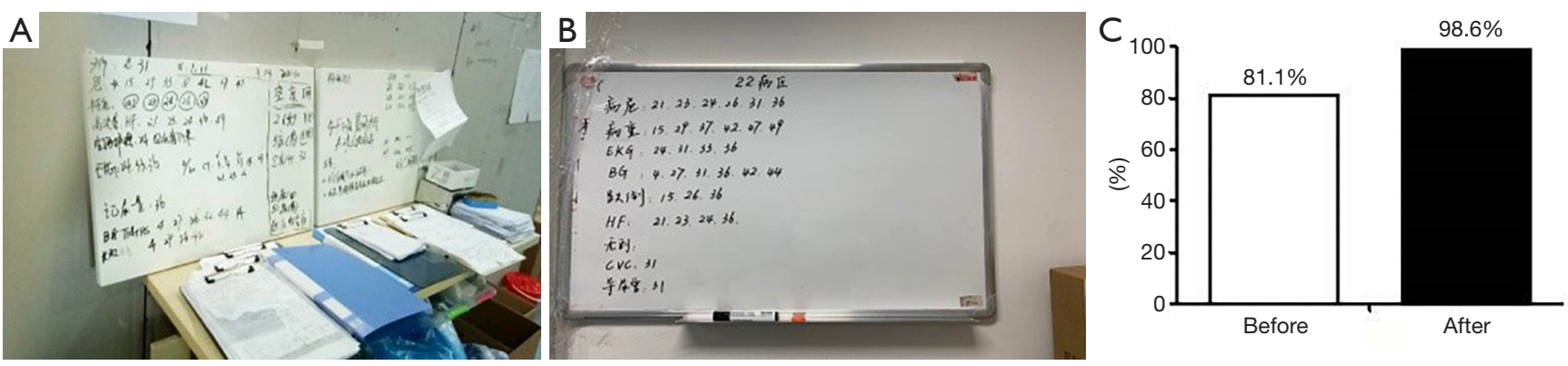

Figure 8 Awareness of medical staff on key nursing information posted on a bulletin board. (A,B) A self-made memo bulletin board was used to list the key points in daily work, (C) the awareness rate on key points increased from $81.1 \%$ to $98.6 \%$.

A

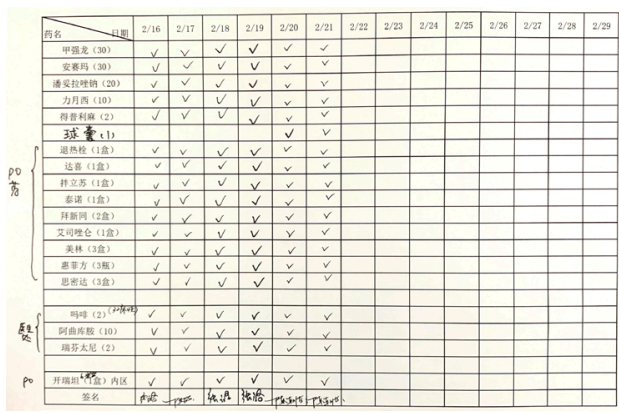

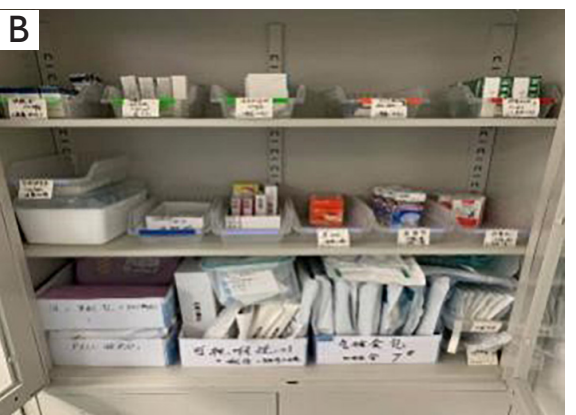

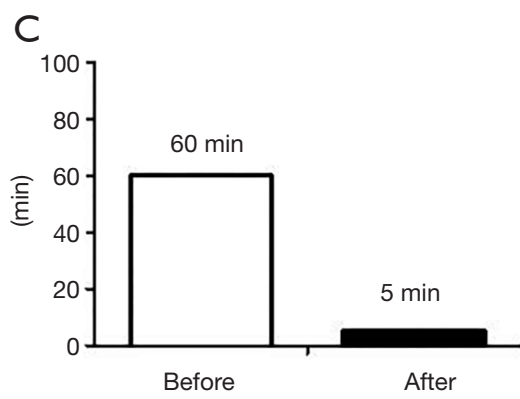

Figure 9 Waiting time for drug transport before and after the implementation of the countermeasure. (A,B) Reserved drugs cabinets were used. (C) The waiting time for drug transport dropped from $60 \mathrm{~min}$ to $5 \mathrm{~min}$ after the countermeasure was implemented.

management in the diagnosis and treatment of a variety of diseases and plays an important role in the standardization of nursing management (11-14). In February 2020, our hospital (Zhongshan Hospital of Fudan University) sent its medical team to Hubei Province to support COVID-19 prevention and control (10) by taking over the ICU of the Department of Infectious Diseases of Eastern Campus,
Renmin Hospital of Wuhan University. This task posed extreme challenges, and, in order to improve the quality and effectiveness of patient treatment and nursing, the aid team established a nursing management team (consisting of 12 nursing staff). Based on the previous experience and the status quo of the ICU, the nursing management team adopted the PDCA cycle to identify the problems, propose 
reasonable and effective suggestions, and implement continuous improvement, so as to ensure the quality and effectiveness of the nursing care.

Nine countermeasures were proposed and implemented accordingly. After 2 weeks of implementation and improvement, the existing problems were effectively addressed and the management of the ICU was gradually standardized, which ensured effective nursing care in the ICU. (I) For the poor awareness of medical staff on contamination and the disorderly placement of shoes, we clearly defined the contaminated areas, semi-contaminated areas, and clean areas, installed self-made shoe cabinets, and offered staff training sessions. After the implementation of these countermeasures, $100 \%$ of the medical staff could identify each area and place their shoes in an orderly manner. This strategy increased the awareness of medical staff on contamination and safeguarded their lives. (II) Based on the professional background of the nursing staff, the management team established specialist nursing teams. Two weeks after the roles and responsibilities of all nurses were defined, the awareness rate of job responsibilities was increased to $100 \%$. We believe that the specialist nursing teams maximized the use of the professional skills of nurses, helped to establish multidisciplinary nursing teams, and implemented a comprehensive and responsive nursing system in the care of COVID-19 patients. Our current study confirmed that this countermeasure was effective and could be included in nursing management norms. (III) To reduce inefficiency and poor communication during shift handover, the management team adopted the SBAR handover sheet and bulletin board in the shift handover to ensure that all the nursing staff could receive handover information quickly and easily. The key points were clearly listed to improve handover communication, eliminate hidden risks, and ensure patient safety. (IV) Long wait times for drug transport was another problem. The management team used reserved drugs cabinets to dramatically shorten the waiting time and improve the efficiency of drug administration. In effect, the use of reserved drug cabinets created a local storage of pharmaceuticals, which saved the time spent in collecting drugs from the pharmacy. Commonly used medicines can be immediately applied to patients, which greatly improves the efficiency of drug administration and enables timely symptom relief. The optimized treatment processes ensures patient safety. This countermeasure was effective and can also be included in nursing management norms.

In addition, a series of training sessions and assessments improved the professionalism and professional skills of nursing staff, which ensured the implementation of nursing measures and improved the quality and effectiveness of nursing.

To our knowledge, this is the first report on PDCA cycle that helps to standardize nursing management in COVID-19 ICU by developing and applying effective nursing management approaches.

In summary, the quality of nursing is closely related to the quality of nursing management. As a useful tool in nursing management, the PDCA cycle helps to standardize nursing management in the COVID-19 ICU by developing and applying effective nursing management approaches.

\section{Acknowledgments}

Funding: This work was supported by the Youth Medical Talents-Nursing Program (grant number [2020] No.087).

\section{Footnote}

Reporting Checklist: The authors have completed the SURGE reporting checklist. Available at http://dx.doi. org/10.21037/apm-20-1084

Data Sharing Statement: Available at http://dx.doi. org/10.21037/apm-20-1084

Conflicts of Interest: All authors have completed the ICMJE uniform disclosure form (available at http://dx.doi. org/10.21037/apm-20-1084). The authors have no conflicts of interest to declare.

Ethical Statement: The authors are accountable for all aspects of the work in ensuring that questions related to the accuracy or integrity of any part of the work are appropriately investigated and resolved. Ethical approval for this study was waived as this study was performed during the COVID-19 epidemic. The nursing team approved the use of the nursing sheets and pictures relevant to this study for this article. All the medical staff participating in this study signed the informed consent documents.

Open Access Statement: This is an Open Access article distributed in accordance with the Creative Commons Attribution-NonCommercial-NoDerivs 4.0 International License (CC BY-NC-ND 4.0), which permits the noncommercial replication and distribution of the article with 
the strict proviso that no changes or edits are made and the original work is properly cited (including links to both the formal publication through the relevant DOI and the license). See: https://creativecommons.org/licenses/by-nc-nd/4.0/.

\section{References}

1. Dai J. Application of PDCA Cycle in nursing management of emergency operating room. China Health Standard Management 2018;13:195-7.

2. Wu Z. Application of PDCA Cycle in improving the quality of nursing in operating rooms. J Clin Med Literature 2016;9:276.

3. He Y. Application value of PDCA Cycle in operating room nursing management. Electronic J Prac Clin Nur Sci 2019;23:169-70.

4. Su Z, Hong C, Wang W, et al. Establishment and management of the hospital critical care groups. J Nur 2014;21:15-6.

5. Yang H, Chao X, Cheng X, et al. The application of PDCA cycle in the teaching management of ICU specialized nurse training. J Nur Administration 2009;9:34-5.

6. Li X. Application of PDCA cycle management mode combined with detail nursing in department of general surgery nursing management. Chin J Prim Med Pharm 2019;26:2293-5.

7. Liu X. Application of PDCA Cycle in nursing management

Cite this article as: Chen Y, Zheng J, Wu D, Zhang Y, Lin Y. Application of the PDCA cycle for standardized nursing management in a COVID-19 intensive care unit. Ann Palliat Med 2020;9(3):1198-1205. doi: 10.21037/apm-20-1084 in interventional operating room. World Lat Med Info 2018;47:263-4.

8. Gao X, Gao M, Zhou Z, et al. Application of PDCA Cycle in the management of intraoperative pressure sore. Chin J Inju Rep Wou Heal 2014;9:17-9.

9. Zhou P, Yang X, Wang X, et al. Discovery of a novel coronavirus associated with the recent pneumonia outbreak in humans and its potential bat origin. bioRxiv 2020. doi: 10.1101/2020.01.22.914952.

10. Huang C Wang Y, Li X, et al, Clinical features of patients infected with 2019 novel coronavirus in Wuhan, China. Lancet 2020;395:497-506.

11. Xie J, Wang J, Chen J, et al. SU-F-T-245: The Investigation of Failure Mode and Effects Analysis and PDCA for the Radiotherapy Risk Reduction. Med Physics 2016;43:3518.

12. Pan L, Yang X, Hong Y. Application of PDCA Management Model in PICC Quality Control for Lung Cancer Patients. J Kunming Med Univ 2014;35:175.

13. Huang W. The application of PDCA Cycle management in quality control of cultural relics protection. Engineering Education and Management, Springer, Berlin, Heidelberg, 2011:625-30.

14. He C, Liu H, Xiang W, et al. Application effect of PDCA circulation management in nursing safety and quality improvement of operation room. J Clin Med in Prac 2017;21:106-8. 